\title{
Erratum to: Prosthetic component segmentation with blur compensation: a fast method for 3D fluoroscopy
}

Giacomo Tarroni - Luca Tersi - Cristiana Corsi •

Rita Stagni

Published online: 25 April 2012

(C) International Federation for Medical and Biological Engineering 2012

Erratum to: Med Biol Eng Comput

DOI 10.1007/s11517-012-0884-x

Due to a processing error, the presentation of Fig. 5 was incorrect. The corrected Fig. 5 is given in the following page.

The online version of the original article can be found under doi:10.1007/s11517-012-0884-x.

G. Tarroni · C. Corsi $(\bowtie) \cdot$ R. Stagni

Department of Electronics, Computer Science, and Systems, (DEIS), University of Bologna, Bologna, Italy

e-mail: cristiana.corsi3@unibo.it

L. Tersi · R. Stagni

Health Sciences and Technologies-Interdepartmental Center for Industrial Research (HST-ICIR), University of Bologna, Bologna, Italy 
Fig. 5 Box and whisker plot of the area ratio $\left(A_{\mathrm{r}}\right)$, mean absolute deviation (MAD), and Hausdorff distance $(H)$ without (step E) and with (step F) blur detection and compensation with respect to different levels of blur and different prosthesis models obtained by one unexperienced operator. The Kolmogorov-Smirnov test highlighted that blur decreased the accuracy of the

segmentation (increasing $H$ and MAD) with a smaller area with respect to the reference contour $\left(A_{\mathrm{r}}<1\right)$. Blur correction and compensation significantly reduced this effect (*MannWhitney $U$ test, $p<0.01$ ) tibial
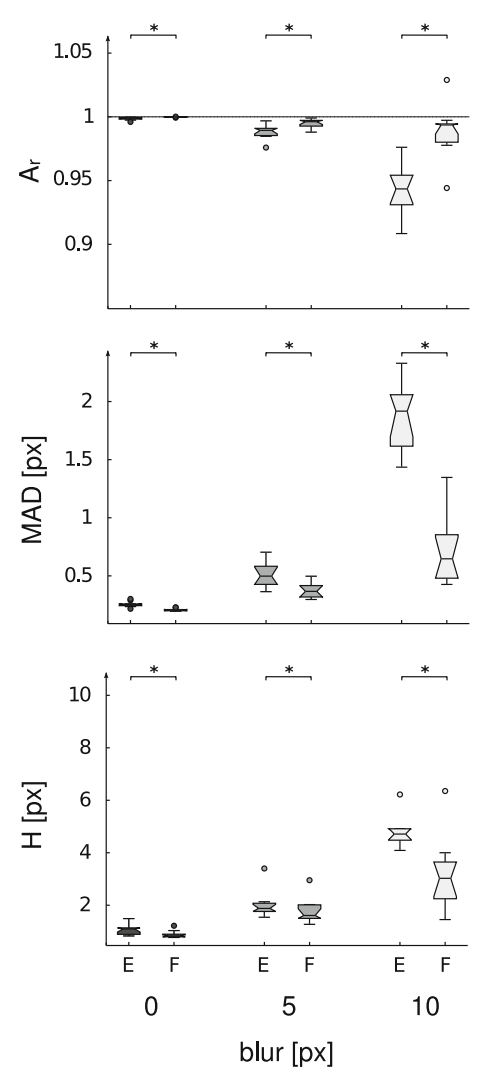

femoral

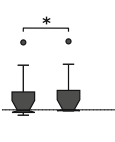

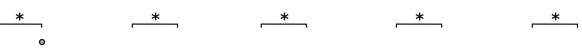<smiles>C#CC#C</smiles><smiles>[CH]1[CH]CC1</smiles><smiles>[Te]C1CCC1</smiles>
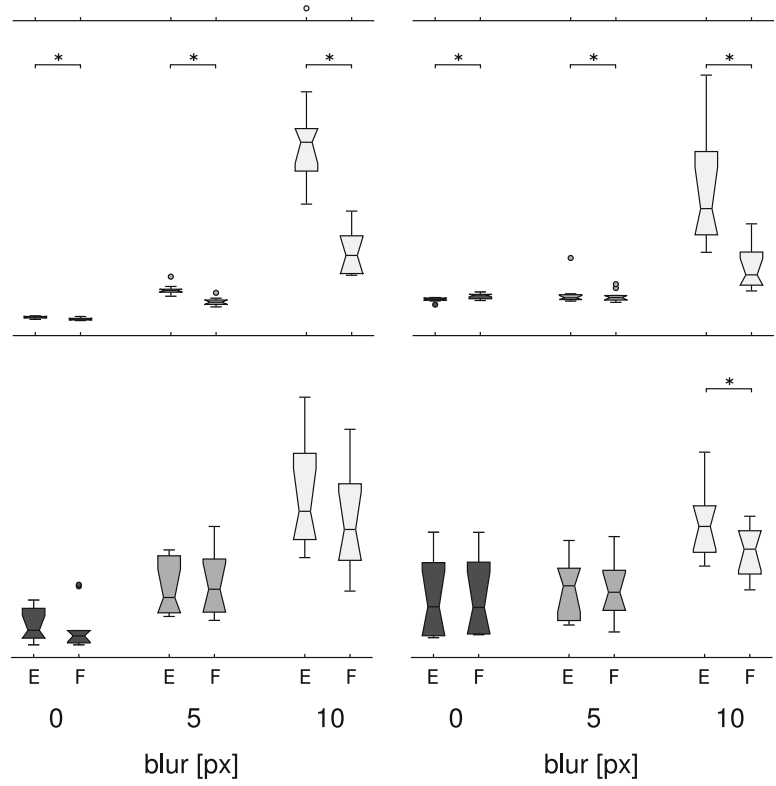